\title{
Особенности электрохимического вольт-фарадного профилирования арсенид-галлиевых светоизлучающих и рНЕМТ-структур с квантово-размерными областями
}

\author{
(ㄷ Г.Е. Яковлев ${ }^{1}$, М.В. Дорохин ${ }^{2}$, В.И. Зубков ${ }^{1}$, А.Л. Дудин ${ }^{3}$, А.В. Здоровейщев ${ }^{2}$, Е.И. Малышева ${ }^{2}$, \\ Ю.А. Данилов ${ }^{2}$, Б.Н. Звонков ${ }^{2}$, А.В. Кудрин ${ }^{2}$ \\ ${ }^{1}$ Санкт-Петербургский государственный электротехнический университет „ЛЭТИ“ им. В.И. Ульянова (Ленина), \\ 197376 Санкт-Петербург, Россия \\ ${ }^{2}$ Научно-исследовательский физико-технический институт \\ Нижегородского государственного университета им. Н.И. Лобачевского, \\ 603950 Нижний Новгород, Россия \\ ${ }^{3}$ Акционерное общество „Светлана-Рост“, \\ 194156 Санкт-Петербург, Россия \\ E-mail: geyakovlev@etu.ru
}

(Получена 21 августа 2017 г. Принята к печати 8 ноября 2017 г.)

\begin{abstract}
Методом электрохимического вольт-фарадного профилирования исследованы квантово-размерные светоизлучающие и транзисторные гетероструктуры на основе GaAs, содержащие области $\delta$-легирования, квантовые ямы InGaAs/GaAs и приповерхностные слои квантовых точек InAs/GaAs. Получены профили распределения концентрации свободных носителей заряда по глубине структур, определены накопленные в квантовой яме и массиве квантовых точек заряды, а также степени легирования эмиттерного и $\delta$-слоев. Проведено моделирование зонной структуры и распределения концентрации носителей заряда по глубине образцов с различной геометрией квантовых ям. Проанализированы особенности электрохимического вольт-фарадного профилирования в гетероструктурах различного типа. Для эффективного разделения откликов от близко расположенных слоев, в частности квантовой ямы и $\delta$-слоя, предложен метод интеграции вольт-фарадных характеристик на каждом этапе травления.
\end{abstract}

DOI: 10.21883/FTP.2018.08.46212.8708

\section{1. Введение}

Несмотря на растущий интерес, поиск и стремление к исследованию и использованию новых полупроводниковых материалов, таких как графен $[1,2]$, полупроводниковый алмаз [3], нитрид бора [4], оксид цинка [5] или поляризационно-легированные широкозонные полупроводники [6,7], наноразмерные гетероструктуры на основе твердых растворов арсенида галлия, в настоящее время занимают главенствующую нишу в ряде областей электроники.

В частности, в спиновой и оптической электронике наибольший интерес вызывают гетероструктуры с квантовыми ямами $(\mathrm{K} Я / \mathrm{QW})$ и самоорганизованными квантовыми точками (КТ) на основе прямозонных полупроводников $\mathrm{A}^{\mathrm{III}} \mathrm{B}^{\mathrm{V}}$. Высокая эффективность излучательной рекомбинации в гетеропарах $\mathrm{InGaAs} / \mathrm{GaAs}$ позволяет использовать их для создания светоизлучающих приборов. Структуры с KT InAs/GaAs весьма привлекательны для волоконно-оптических линий связи в диапазоне длин волн $1.3-1.55$ мкм $[8,9]$ благодаря ряду преимуществ, среди которых высокая температурная стабильность люминесценции, сравнительно высокие время жизни и время сохранения спина носителей заряда.

Другим примером являются полевые транзисторы pHEMT (pseudomorphic high-electron-mobility transistor) с двумерным электронным газом высокой плотности на основе псевдоморфно напряженных КЯ $\mathrm{AlGaAs} / \mathrm{InGaAs} /$
GaAs, широко применяемые в настоящее время для разработки и создания приборов СВЧ электроники частотного диапазона 4-18ГГц (усилители, смесители, умножители частоты, управляющие устройства и т.д.) [10-12]. В данном частотном диапазоне отечественные разработки рНЕМТ соответствуют зарубежным и решают проблему недоступности СВЧ приборов для разработчиков и производителей радиоэлектронной аппаратуры.

Электрические, оптические и структурные свойства полупроводниковых приборов в значительной степени определяются уровнем их легирования, типом легирующей примеси и характером ее распределения. Среди ряда методик контроля уровня легирования и пространственного распределения основных носителей заряда (ОН3) метод электрохимического вольт-фарадного профилирования (ECV-метод) выделяется широким диапазоном измерения концентрации носителей заряда (от $10^{12}$ до $10^{21} \mathrm{~cm}^{-3}$ ) на глубинах от единиц нм до десятков мкм [13-15]. В основе ECV-метода лежит чередование процессов вольт-фарадных измерений и электрохимического травления, а отличительной чертой является отсутствие необходимости нанесения металлических контактов на образец. Выпрямляющий контакт полупроводник/электролит образует переход, схожий с контактом Шоттки. Метод ECV входит в стандарты международной ассоциации поставщиков полупроводниковой промышленности SEMI и эффективно применяется 


\begin{tabular}{|lr|}
\multicolumn{2}{c}{ I } \\
\hline GaAs undoped & $140 \mathrm{~nm}$ \\
\hline InGaAs & $10 \mathrm{~nm}$ \\
\hline GaAs undoped & $13 \mathrm{~nm}$ \\
\hline$\delta$-GaAs: C \\
\hline GaAs undoped & $240 \mathrm{~nm}$ \\
\hline GaAs $(C)$ & $480 \mathrm{~nm}$ \\
\hline$p^{+}$-GaAs substrate \\
\hline
\end{tabular}

II

\begin{tabular}{|lr|}
\hline GaAs & $25 \mathrm{~nm}$ \\
\hline InAs: $\mathrm{Mn}(\mathrm{Cr})$ QD \\
\hline GaAs & $20 \mathrm{~nm}$ \\
\hline GaAs buffer & $250 \mathrm{~nm}$ \\
\hline GaAs substrate \\
\hline
\end{tabular}

III

\begin{tabular}{|lr|}
\hline$n$-GaAs & $8.5 \mathrm{~nm}$ \\
\hline$n$-AlGaAs stop & $2.5 \mathrm{~nm}$ \\
\hline$n$-GaAs & $5 \mathrm{~nm}$ \\
\hline$n$-AlGaAs & $15 \mathrm{~nm}$ \\
\hline$n$-AlGaAs emitter & $12.5 \mathrm{~nm}$ \\
\hline$n$-GaAs & $1.5 \mathrm{~nm}$ \\
\hline InGaAs QW & $12 \mathrm{~nm}$ \\
\hline GaAs & $3 \mathrm{~nm}$ \\
\hline AlGaAs emitter & $12.5 \mathrm{~nm}$ \\
\hline AlGaAs buffer & $90 \mathrm{~nm}$ \\
\hline GaAs buffer & $800 \mathrm{~nm}$ \\
\hline GaAs substrate & \\
\hline
\end{tabular}

Рис. 1. Схематическое послойное изображение структур трех типов исследуемых образцов.

для исследования различных полупроводниковых структур, в том числе структур с КЯ, КТ и $\delta$-легированными слоями [16,17].

Основной целью настоящей работы являлось изучение особенностей пространственного распределения ОНЗ в гетероструктурах с симметричными (светоизлучающие структуры) и несимметричными (рНЕМТ-структуры) квантовыми ямами InGaAs одинакового состава, а также анализ особенностей резко неоднородного легирования в гетероструктурах с массивами квантовых точек и $\delta$-слоями, проявляющихся в $\mathrm{ECV}$-измерениях.

\section{2. Образцы и техника эксперимента}

В рамках данной работы нами исследовались три типа гетероструктур: светоизлучающие структуры с симметричной КЯ $\mathrm{In}_{0.22} \mathrm{Ga}_{0.78} \mathrm{As} / \mathrm{GaAs}$ и $\delta$-легированным слоем (тип I), светоизлучающие структуры с массивом самоорганизованных KT InAs/GaAs (тип II) и pHEMT-структуры с несимметричной КЯ $\mathrm{In}_{0.22} \mathrm{Ga}_{0.78} \mathrm{As} / \mathrm{GaAs} / \mathrm{AlGaAs}$ (тип III).

\section{1. Светоизлучающие гетероструктуры с квантовыми ямами InGaAs/GaAs}

Исследуемые в работе квантово-размерные структуры на основе гетеросистемы InGaAs/GaAs получены методом МОС-гидридной эпитаксии (газофазной эпитаксии из металлоорганических соединений) на подложках из $p^{+}$-GaAs марки АГЧЦ при температуре ростового процесса $620^{\circ} \mathrm{C}$. Схематическое послойное изображение структуры исследуемых образцов представлено на рис. 1 (тип I). Образец 1 содержал квантовую яму $\mathrm{In}_{0.22} \mathrm{Ga}_{0.78} \mathrm{As}$ (толщиной 10 нм) и область $\delta$-легирования, созданную внедрением примеси углерода. В качестве образцов сравнения выступали структуры только с одиночным $\delta$-слоем (образец 2) и только с одиночной квантовой ямой $\operatorname{In}_{0.3} \mathrm{Ga}_{0.7} \mathrm{As}$ (образец 3 ). Образец 3 выращен на $p^{+}$-подложке с повышенным уровнем легирования и сформирован с толстым (750 нм) верхним нелегированным эпитаксиальным слоем. Более детальное описание данных образцов можно найти в [18].

\section{2. Светоизлучающие гетероструктуры с квантовыми точками InAs/GaAs}

На гетероструктурах с квантовыми точками InAs/GaAs, выращенных на подложках GaAs методом MOC-гидридной эпитаксии при атмосферном давлении, исследовались электрические свойства массива КТ в зависимости от степени их легирования примесями. Схематическое изображение образцов представлено на рис. 1 (тип II). Массив самоорганизованных КТ выращивался при температуре $520^{\circ} \mathrm{C}$. Пониженная температура, как показали наши предыдущие исследования $[8,19,20]$, обеспечивает формирование массива однородных КТ. Слой квантовых точек заращивался покровным слоем GaAs толщиной 25 нм. В пару к образцу с сильно легированной подложкой $n$-типа проводимости (образец 4) был сформирован образец сравнения 5 на полуизолирующей подложке. Легирование КТ для придания им дырочной проводимости осуществлялось в процессе выращивания методом распыления из мишени $\mathrm{Mn}$ импульсным $\mathrm{Nd}$ : YAG-лазером. Концентрация примеси марганца варьировалась путем изменения интенсивности лазерного излучения в процессе роста $[21,22]$.

\section{3. Гетероструктуры рHЕMT InGaAs/GaAs/AIGaAs}

Серия приборных рНЕМТ-гетероструктур InGaAs/ $\mathrm{GaAs} / \mathrm{AlGaAs}$ с двухсторонним легированием (эмиттерный слой) в окрестности квантовой ямы (тип III) была выращена на полуизолирующих подложках $\mathrm{GaAs}$ (100) методом молекулярно-пучковой эпитаксии. Образцы были практически идентичными (рис. 1) и различались только уровнем легирования эмиттерного слоя 
$n$-AlGaAs. В частности, подробно анализируемый далее образец 6 был легирован до уровня $\sim 3 \cdot 10^{18} \mathrm{~cm}^{-3}$. Квантовая яма $\mathrm{In}_{0.22} \mathrm{Ga}_{0.78} \mathrm{As} / \mathrm{GaAs}$ располагалась на глубине $(54.5 \pm 0.5)$ нм и имела ширину 12 нм.

\section{4. Техника эксперимента}

Измерения распределения концентрации основных носителей заряда по глубине гетероструктур проводились при комнатной температуре с использованием установки электрохимического профилирования ECVPro (Nanometrics). В ряде экспериментов для измерения вольт-фарадных характеристик использовался LCR-измеритель Agilent E4980A, который подключался к электрохимической ячейке установки ECVPro через сконструированный блок реле [7]. В качестве электролита для проведения ECV-исследований был выбран водный раствор $0.1 \mathrm{M}$ тайрона. Данный раствор является полирующим травителем для GaAs и обеспечивает прецизионное травление материала с оптимальной скоростью. Площадь электролитического контакта составляла $0.1 \mathrm{~cm}^{2}$. Частота и амплитуда переменного тестового сигнала выбирались 300 Гц и $100 \mathrm{MB}$ соответственно. Травление в сильно легированных областях полупроводника проводилось с шагом 1 нм. Контроль глубины травления и качества поверхности осуществлялся при помощи атомно-силового микроскопа (ACM) Solver NEXT.

\section{3. Экспериментальные данные и обсуждение}

\section{1. Светоизлучающие структуры с квантовыми ямами $\ln \mathrm{GaAs} / \mathrm{GaAs}$}

Ha рис. 2 представлен полученный ECV-методом профиль концентрации ОН3 по глубине $x$ образца 1, содержащего квантовую яму $\mathrm{InGaAs} / \mathrm{GaAs}$ и область $\delta$-легирования, созданную внедрением в арсенид галлия примеси углерода. Как видно, ECV-метод позволяет построить зависимость распределения концентрации ОНЗ

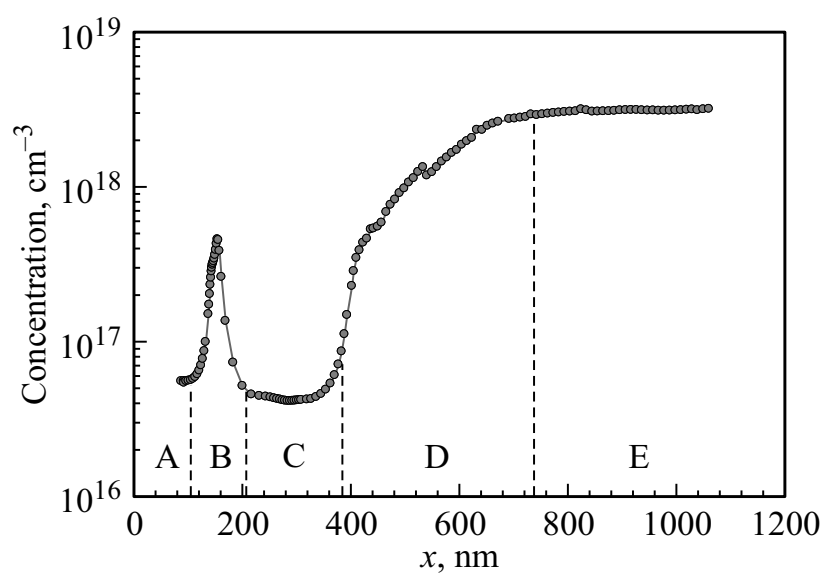

Рис. 2. Профиль распределения концентрации ОНЗ по глубине образца 1.

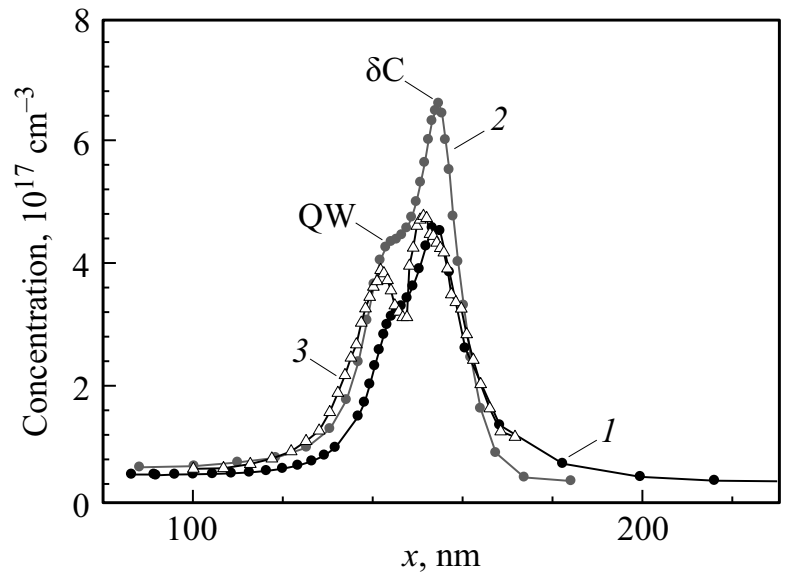

Рис. 3. Профили распределения концентрации ОНЗ вблизи КЯ InGaAs и $\delta$-слоя $(\delta \mathrm{C})$ в образце $1: 1-$ измерения методом $\mathrm{ECV}, 2$ - измерения методом ВФХ, 3 - суперпозиция ВФХ, измеренных на различных глубинах.

по глубине для всех эпитаксиальных слоев структуры, а также в подложке. На общем распределении концентрации ОНЗ по глубине структуры (см. рис. 2) можно выделить пять участков: участок А вблизи поверхности структуры - область нелегированного покровного слоя GaAs c концентрацией носителей заряда $\sim 6 \cdot 10^{16} \mathrm{~cm}^{-3}$; участок В - суперпозиция двух близко расположенных пиков, соответствующих областям локализации носителей заряда в квантовой яме InGaAs и $\delta$-слое; участок C протяженностью $\sim 180$ нм - область нелегированного GaAs (спейсера) с концентрацией носителей заряда $\sim 4 \cdot 10^{16} \mathrm{~cm}^{-3}$; участок D протяженностью $\sim 400 \mathrm{HM}-$ область буферного слоя $\mathrm{GaAs}$, легированного акцепторной примесью углерода, с концентрацией носителей заряда от $7 \cdot 10^{17}$ до $3 \cdot 10^{18} \mathrm{~cm}^{-3}$; участок $\mathrm{E}$ - подложка с концентрацией носителей заряда $3 \cdot 10^{18} \mathrm{~cm}^{-3}$. Заметим, что найденная концентрация носителей заряда в подложке близка к результатам, полученным измерениями методом эффекта Холла [18].

Подробнее участок В представлен на рис. 3. Вследствие близкого взаимного расположения квантовой ямы и $\delta$-слоя происходит значительное перекрытие соответствующих областей локализации подвижных носителей заряда. Это препятствует разделению двух концентрационных пиков при ECV-профилировании в режиме травления (etching mode) и в измерениях емкости при фиксированном напряжении двухчастотным методом, реализованным в ECV-профилометре. В данной работе, чтобы повысить разрешение, мы реализовали метод, заключающийся в измерениях на каждой глубине травления вольт-фарадных характеристик во всем доступном диапазоне напряжений и получении путем их суперпозиции результирующего профиля концентрации (рис. 3 , кривая 3).

Анализируя концентрационные профили, полученные из вольт-фарадных характеристик, измеренных по мере травления слоев полупроводниковой структуры, можно 
Характеристики концентрационных профилей измеренных образцов с КЯ

\begin{tabular}{|c|c|c|c|c|}
\hline $\begin{array}{l}\text { Номер } \\
\text { образца }\end{array}$ & $\begin{array}{c}\text { Глубина } \\
\text { травления, нм }\end{array}$ & 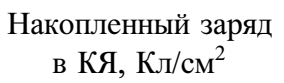 & $\begin{array}{c}\text { Накопленный заряд } \\
\text { в } \delta \text {-слое, Кл/см² }\end{array}$ & $\begin{array}{c}\text { FWHM концентрационного } \\
\text { пика от КЯ/ } \delta \text {-слоя, нм }\end{array}$ \\
\hline $\begin{array}{l}1 \\
2 \\
3\end{array}$ & $\begin{array}{l}- \\
- \\
-\end{array}$ & $\begin{array}{c}1 \cdot 10^{12} \\
- \\
5.5 \cdot 10^{11}\end{array}$ & $\begin{array}{c}1.8 \cdot 10^{12} \\
2 \cdot 10^{12} \\
-\end{array}$ & $\begin{array}{c}15 / 14 \\
26 \\
41\end{array}$ \\
\hline 6 & $\begin{array}{r}0 \\
4 \\
7 \\
16\end{array}$ & $\begin{array}{c}- \\
1 \cdot 10^{12} \\
1.7 \cdot 10^{12} \\
2 \cdot 10^{12}\end{array}$ & $\begin{array}{l}- \\
- \\
- \\
-\end{array}$ & $\begin{array}{r}- \\
16 \\
12 \\
8\end{array}$ \\
\hline
\end{tabular}

заметить следующее. При небольших глубинах травления не удается достигнуть высокого разрешения по концентрации в области, соответствующей глубоко залегающим слоям структуры (области КЯ). Это обусловлено большим значением фактора диссипации из-за преобладания вклада активного сопротивления толстых верхних слоев. Напротив, измерение вольт-фарадных характеристик (ВФХ) после стравливания верхних слоев позволяет создать условия, когда почти вся полная проводимость обусловлена ее реактивной частью. В этом случае малое приращение напряжения $\Delta U$ приводит к значительным изменениям емкости $\Delta C$ и соответственно к большей чувствительности. Ранее [23] нами для прецизионного измерения ВФХ одиночных КЯ оптимизировались параметры верхнего слоя структур (толщина и концентрация примеси в нем) так, чтобы ВФХ в диапазоне минимальных токов через диод позволила зарегистрировать весь профиль концентрации носителей заряда в области КЯ. В настоящей работе задача решается путем технологического стравливания верхнего слоя до нужной толщины в течение эксперимента. В частности, при измерении образца 1 мы использовали ВФХ от трех областей: верхние слои до КЯ, область квантовой ямы и $\delta$-слой, нижние слои после $\delta$-слоя. Это позволило уверенно различить близко расположенные пики, связанные с квантовой ямой и $\delta$-слоем [24]. При этом разница между концентрацией в пике отклика от КЯ и концентрацией в области провала между КЯ и $\delta$-слоем составляет $20 \%$, что подтверждает уверенное разделение двух пиков и показывает перспективность предлагаемого метода определения концентрации в случае наличия тонкой структуры в концентрационном профиле.

Для сравнения полученных данных нами были проведены измерения данного образца классическим вольт-фарадным методом с помощью автоматизированного комплекса спектроскопии адмиттанса на базе LCR-метра Agilent E4980A [25]. Результат также представлен на рис. 3 (кривая 2). Для этого на структуру дополнительно были нанесены металлические омический и выпрямляющий (Шоттки) контакты. Как видно из рисунка, ECV-профиль уширен и имеет меньшую амплитуду по сравнению с результатом классических вольт-фарадных измерений. Это может быть объяснено известной инерционностью режима измерений в случае электролитического контакта. Расчет накопленного заряда в области КЯ и $\delta$-слоя с учетом дебаевского размытия показывает одинаковый результат в пределах погрешности используемых методов.

Верификация результатов проводилась путем самосогласованного моделирования вольт-фарадных характеристик структур с близко расположенными КЯ и $\delta$-слоем по алгоритму, описанному в $[14,26]$. Кроме отмеченной особенности некоторого уширения ECV-профиля в экспериментальных зависимостях наблюдалось отсутствие областей обеднения ОНЗ, обычно наблюдающихся по обеим сторонам квантовой ямы [26].

На рис. 4 представлены ECV-профили распределения подвижных носителей заряда в образцах 2 и 3, содержащих одиночный $\delta$-слой (кривая 1 ) и одиночную квантовую яму InGaAs/GaAs (кривая 2) соответственно. Заметим, что в образце 3 с глубоко расположенной КЯ ее профилирование классическим методом ВФХ не представляется возможным ввиду наступления обратного пробоя структуры. Отсутствие провалов на концентрационном профиле в соседних с КЯ областях (кривая 2) мы объясняем особенностями двухчастотного метода измерения в режиме травления нелегированных слоев. Пиковая концентрация ОНЗ в $\delta$-слое равна $6 \cdot 10^{17} \mathrm{~cm}^{-3}$, в КЯ $-5 \cdot 10^{16} \mathrm{~cm}^{-3}$. Области минимума концентра-

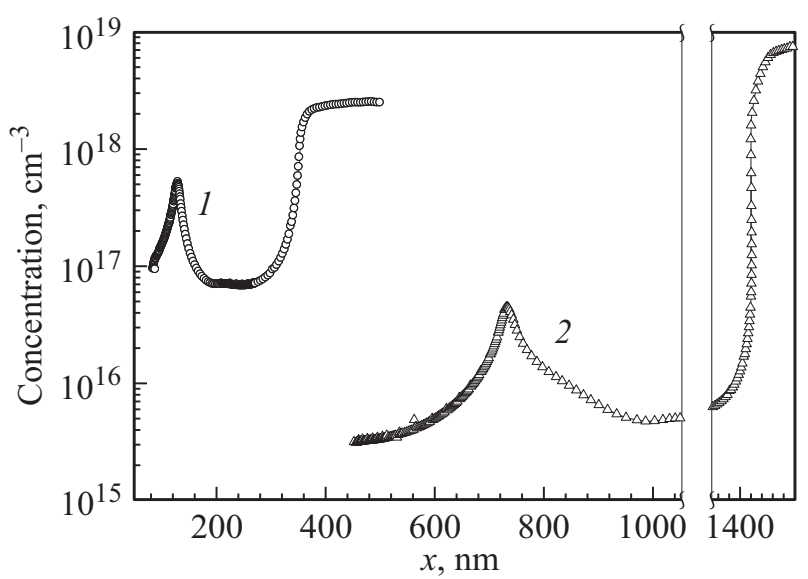

Рис. 4. Профили распределения концентрации ОНЗ по глубине: 1 - образец 2 с $\delta$-слоем, 2 - образец 3 с КЯ. 
ции связаны, как обсуждалось ранее, с нелегированным покровным и буферным слоями GaAs. Наличие узкого эпитаксиального слоя с областью $\delta$-легирования приводит к существенному увеличению наблюдаемой концентрации ОНЗ в этих слоях. Далее наблюдается выход на максимальную концентрацию, определяемую буферным слоем и подложкой $p$-типа проводимости.

Результаты оценки накопленного заряда в КЯ и $\delta$-слое согласно методике, описанной в [27], для образцов 1-3 представлены в таблице. Как и следовало ожидать, величина аккумулируемого в КЯ заряда существенно меньше по сравнению с зарядом, содержащимся в $\delta$-слое.

\section{2. Транзисторные рНЕМТ-структуры на основе GaAs}

Для сравнительного анализа пространственного распределения ОНЗ в КЯ различной геометрии ECV-методом нами исследовались рНЕМТ-структуры на основе GaAs с несимметричной КЯ InGaAs аналогичного состава. На рис. 5 представлена эволюция концентрационных профилей в зависимости от глубины травления (образец 6), шаг травления 2 нм. Как видно из полученных профилей ОНЗ, в определенном диапазоне глубин травления $(d=8-20 \mathrm{Hм})$ удается четко разделить близко расположенные концентрационные пики от эмиттерного слоя и от КЯ.

Концентрационный пик, связанный с эмиттерным слоем (расположен на глубине $\sim 38$ нм от исходной поверхности, рис. 1), имеет амплитуду $3.1 \cdot 10^{18} \mathrm{~cm}^{-3}$, которая не зависит от глубины травления поверхностного слоя. В противовес этому нами впервые методом $\mathrm{ECV}$ обнаружена и проанализирована закономерность, заключающаяся в изменении амплитуды концентрационного пика, связанного с КЯ (см. вставку на рис. 5). Изменение амплитуды вызывается изменением степени заполнения энергетических подзон квантовой ямы носителями заряда по мере стравливания верхних слоев. Данная особенность воспроизводится на различных GaAs-pHEMT-структурах. Следует заметить, что данный эффект не наблюдался в светоизлучающих структурах, описанных в разд. 3.1, и является отличительной чертой именно рНЕМТ-структур. Это имеет конкретное практическое значение, поскольку может быть использовано для контролируемого утончения подзатворной области рНЕМТ-структур с целью насыщения КЯ носителями заряда, увеличения проводимости канала и рабочего тока конечного прибора [28]. С этой точки зрения оптимальной величиной утончения верхних слоев для исследуемых рНЕМТ-структур является 16 нм. Заметим, что травление в ECV-эксперименте проводится лишь в малой области диаметром 3 мм, тем самым моделируются условия реальной технологии локального утончения слоев полевого прибора в области затвора.

Важно отметить также, что пик, соответствующий эмиттерному слою, в подобных структурах удается зарегистрировать только методом ECV. В существующих

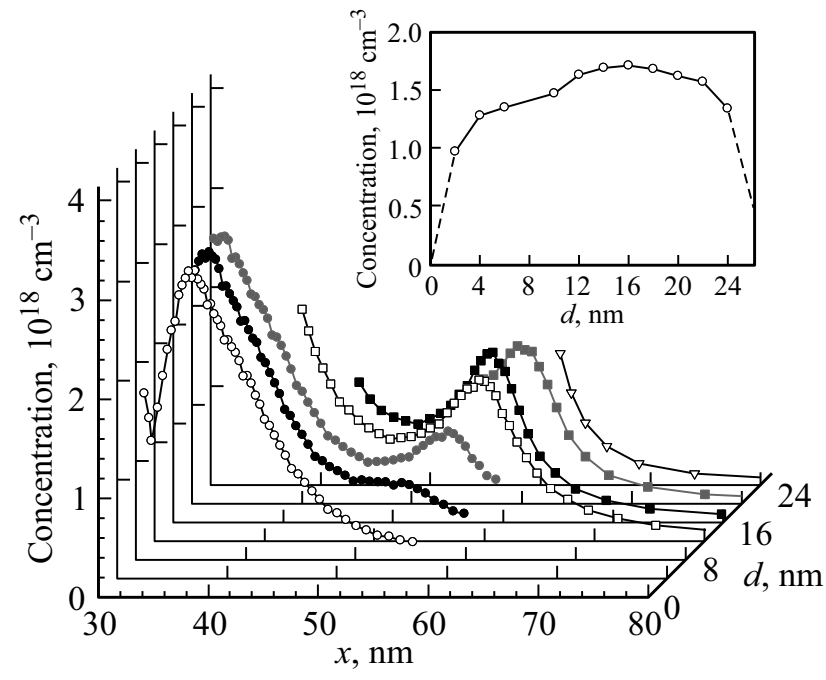

Рис. 5. Эволюция измеренных профилей распределения концентрации ОНЗ образца 6 по мере утончения верхних слоев структуры. На вставке - изменение амплитуды концентрационного пика, связанного с КЯ.

публикациях классическим методом ВФХ наблюдается только один пик на концентрационном профиле рНЕМТ-структур, приписываемый области КЯ (2DEG канала) [29]. Наличие двух пиков в наших измерениях объясняется тем, что жидкий электролит создает на поверхности меньший выпрямляющий барьер по сравнению с металлическим контактом при классическом вольт-фарадном профилировании, поэтому исходная (при $U=0)$ ширина обедненной области оказывается меньше [30].

В таблице также представлена информация об уровне заполнения носителями заряда квантовой ямы в зависимости от глубины травления образца 6. Анализ показывает, что профили распределения концентрации ОНЗ уширены на величину дебаевского размытия, при этом полученные результаты хорошо коррелируют с паспортными данными выращенной структуры, а имеющееся незначительное несовпадение по координате ( $<5$ нм) может быть связано с особенностью профилирования несимметричной КЯ методом ECV [31]. Как и ожидалось для рНЕМТ-структур, накопленный в КЯ заряд, в зависимости от величины утончения подзатворных слоев до 2 раз больше по сравнению со светоизлучающими структурами. Очевидно, больший накапливаемый заряд при схожем по порядку уровне легирования смежных с КЯ областей объясняется бо́льшим разрывом зон на гетерогранице $\mathrm{AlGaAs} / \mathrm{InGaAs}$ и несимметричной геометрией КЯ.

Для анализа электронной структуры КЯ нами были проведены измерения фотолюминесценции (ФЛ) при различных температурах и их численное моделирование [32]. В измеренных спектрах ФЛ наблюдались два пика различной интенсивности в области длины волны 1000 нм. Эти пики формируются вследствие рекомбинации электронов из первой и второй подзон размерного 
квантования зоны проводимости КЯ с дырками валентной зоны. Сопоставление расчетных и наблюдаемых спектров ФЛ также показало, что в ходе эпитаксиального роста удалось избежать сегрегации как индия, так и кремния, а также вызываемых ими искажений формы квантовой ямы [30].

\section{3. Светоизлучающие структуры с квантовыми точками InAs/GaAs}

В третьей части работы анализировались особенности заполнения квантовых точек носителями заряда в зависимости от легирующей примеси. Результаты исследования образцов светоизлучающих гетероструктур с массивом самоорганизованных KT InAs/GaAs, сформированных на глубине 25 нм от поверхности, представлены на рис. 6. На обоих профилях на соответствующем расстоянии от поверхности наблюдаются максимумы концентрации дырок. Как правило, в вольт-фарадных измерениях положение измеренного концентрационного отклика от КТ сдвинуто в глубь структуры относительно его реального положения из-за наличия так называемого $\lambda$-слоя [14]. В нашем случае высоколегированной структуры толщина $\lambda$-слоя, в соответствии с соображениями [14], оказывается малой, так что укладывается в погрешность измерений и технологического разброса параметров структур.

В случае структуры без дополнительного акцепторного легирования слоя КТ (образец 4) концентрация дырок в максимуме составляет $3 \cdot 10^{18} \mathrm{~cm}^{-3}$ (кривая 1). Такая достаточно высокая концентрация ОНЗ в приповерхностной области обусловлена большой величиной разрыва зон в слое квантовых точек и высокой степенью пространственного ограничения носителей заряда. Введение марганца в область квантовых точек (образец 5) приводит к дополнительному увеличению общей концентрации дырок почти на порядок величины. Поверхностная плотность атомов $\mathrm{Mn}$, согласно технологическим параметрам роста, задавалась на уровне $8 \cdot 10^{12} \mathrm{~cm}^{-3}$, что соответствует объемной концентрации $\sim 2.3 \cdot 10^{19} \mathrm{~cm}^{-3}$. Эта величина хорошо согласуется с измеренным значением концентрации $1.5 \cdot 10^{19} \mathrm{~cm}^{-3}$ и свидетельствует о том, что бо́льшая часть примеси встроилась в узлы кристаллической решетки. Данная информация является очень полезной для прогнозирования свойств реальных приборов оптоэлектроники, так как существует определенная вероятность встраивания марганца в междоузлия, где он в таком случае является двойным донором. Высокая степень локализации носителей заряда в КТ также подтверждается спектрами ФЛ, измеренными при комнатной температуре. В спектре наблюдается широкая полоса с максимумом при энергии квантов $\sim 0.97$ эВ, соответствующая излучательным переходам в КT InAs.

В образце 4 по мере удаления от поверхности (область 100-350 нм) наблюдается снижение концентрации дырок до $\sim 10^{17} \mathrm{~cm}^{-3}$, однако при этом тип проводи-

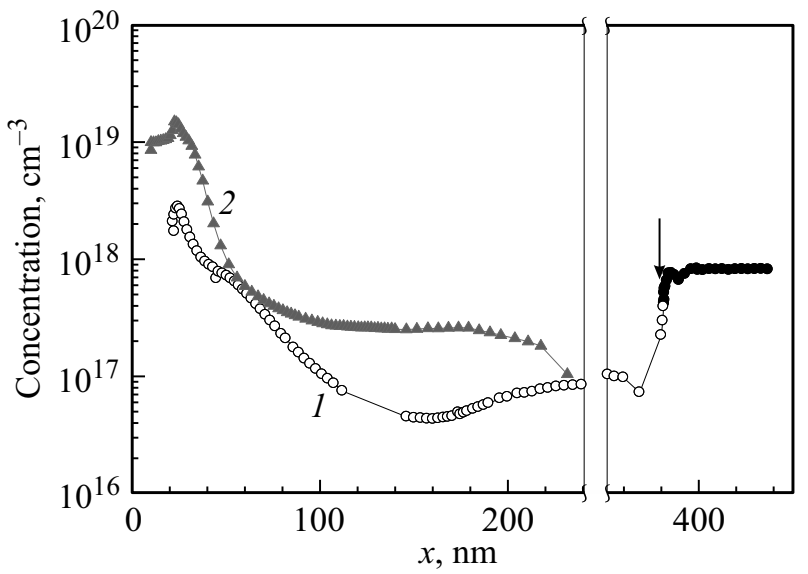

Рис. 6. Профили распределения концентрации носителей заряда по глубине образцов с квантовыми точками: 1 образец 4, 2 - образец 5.

мости не изменяется. Таким образом, измерения выявляют проводимость $p$-типа в номинально легированном донорной примесью буферном слое. По-видимому, причиной разногласий в технологических и измеряемых параметрах является наличие фоновой примеси акцепторного типа в реакторе. В результате этого в процессе роста имели место перекомпенсация и изменение типа проводимости. На расстоянии $\sim 350$ нм от поверхности происходит смена типа проводимости на электронную и увеличение концентрации до $7 \cdot 10^{17} \mathrm{~cm}^{-3}$. Смена типа проводимости на кривой 1 отмечена стрелкой. Расстояние, на котором происходит смена типа проводимости, примерно соответствует глубине буферного и покровного слоев, выращенных на подложке $n$-GaAs. Таким образом, можно предположить, что измеренная концентрация электронов на глубине 400 нм соответствует их концентрации в подложке GaAs. Заметим, что возможность измерения концентрации разноименных типов носителей заряда в рамках одного эксперимента недоступна в классическом вольт-фарадном профилировании и является отличительной особенностью метода ECV. Это становится возможным за счет операции травления, когда перманентно происходит изменение граничных условий на поверхности структуры, и при проходе через $p-n$-переход мы наблюдаем смену наклона ВФХ [16].

Аналогично предыдущей структуре в образце 5 по мере удаления от поверхности наблюдается спад концентрации ОНЗ. В области 50-250 нм, соответствующей буферному слою GaAs, была получена концентрация дырок $p=2 \cdot 10^{17} \mathrm{~cm}^{-3}$. Дальнейшее снижение концентрации свободных носителей свидетельствует об измерении концентрации в полуизолирующей подложке GaAs.

Для анализа условий применимости ECV-метода в случае полуизолирующих структур с компенсирующей примесью нами также измерялись образцы с квантовыми точками InAs, легированными Cr. Известно, что в отличие от марганца введение глубокой примеси хрома вызывает кардинальное снижение концентрации 
свободных носителей заряда [33]. Соответственно это приводит к увеличению толщины обедненного слоя и резкому уменьшению емкости структуры практически до пределов ее возможной регистрации существующими измерителями емкости. Применение метода ECV на границе разрешающей способности позволило сделать оценку концентрации ОНЗ в структурах, легированных хромом, - ее значение лежит ниже $10^{12} \mathrm{~cm}^{-3}$.

\section{4. Заключение}

В ходе выполнения работы методом электрохимического вольт-фарадного профилирования исследовались квантово-размерные светоизлучающие и транзисторные гетероструктуры на основе GaAs, содержащие $\delta$-слои, квантовые ямы $\mathrm{AlGaAs} / \mathrm{InGaAs} / \mathrm{GaAs}$ и приповерхностные квантовые точки InAs/GaAs. Показана эффективность ECV-метода для нахождения детального распределения концентрации основных носителей заряда и толщины слоев в гетероструктурах с КЯ и КТ.

Получены зависимости распределения концентрации носителей заряда по глубине структур, определены положение и степень легирования КЯ, массива КТ, эмиттерных и $\delta$-слоев. Для уверенного разделения близко расположенных пиков, связанных с квантовой ямой и $\delta$-слоем или квантовой ямой и эмиттерным слоем, предложен метод интегрирования вольт-фарадных характеристик на каждом этапе травления с последующим пересчетом в результирующий профиль распределения ОНЗ.

Впервые методом ECV обнаружена зависимость степени заполнения носителями заряда КЯ в рНЕМТ-структурах от глубины травления. Данная особенность может быть использована для контролируемого утончения подзатворной области рНЕМТ-структур с целью насыщения КЯ носителями заряда, увеличения проводимости канала и рабочего тока конечного прибора. Для рассмотренных pНЕМТ-структур оптимальной глубиной утончения поверхностных слоев является 16 нм. Сравнением накопленного заряда в КЯ светоизлучающих и рНЕМТ-структур, установлено, что у последних, в зависимости от величины утончения подзатворного слоя, это значение может быть до 2 раз больше.

В образцах с KT InAs/GaAs EVC-методом обнаружена проводимость $p$-типа в области номинально не легированного (образец 5) и легированного донорной примесью (образец 4) буферных слоев. Мы связываем это с присутствием фоновой примеси в реакторе, перекомпенсацией основной легирующей примеси и результирующим изменением типа проводимости структуры.

Для образцов KT InAs/GaAs с компенсирующей примесью хрома получена оценка минимального уровня легирования структур, который возможно зарегистрировать с помощью ECV-метода.

Коллектив авторов выражает особую благодарность канд. физ.-мат. наук Д.С. Фролову (Elmos Semiconductor $\mathrm{AG)}$ за помощь в измерениях и ценные консультации при написании данной статьи.
Работа выполнена в рамках реализации проекта № 8.1751.2017/ПЧ Министерство образования и науки России, соглашения № 14.582.21.0010 Министерство образования и науки России (идентификатор проекта RFMEFI58215X0010), при поддержке РФФИ (гранты № 15-02-07824_a, 16-07-01102_a), гранта президента Российской Федерации (МК-8221.2016.2), а также при финансовой поддержке СПбГЭТУ „ЛЭТИ“ (мероприятие М.5.1.2).

\section{Список литературы}

[1] A.K. Geim, K.S. Novoselov. Nature Materials, 6, 183 (2007).

[2] A.K. Geim. Science, 324, 1530 (2009).

[3] V.I. Zubkov, O.V. Kucherova, A.V. Zubkova, J.E. Butler, V.A. Ilyin, A.V. Afanas'ev, S.A. Bogdanov, A.L. Vikharev. J. Appl. Phys., 118, 145703 (2015).

[4] G. Cassabois, P. Valvin, B. Gil. Nature Photonics, 10, 262 (2016).

[5] B.K. Meyer, H. Alves, D.M. Hofmann, W. Kriegseis, D. Forster, F. Bertram, J. Christen, A. Hoffmann, M. Straßburg, M. Dworzak, U. Haboeck, A.V. Rodina. Phys. Status Solidi B, 241, 231 (2004).

[6] Н.В. Кузнецова, Д.В. Нечаев, Н.М. Шмидт, С.Ю. Карпов, Н.В. Ржеуцкий, В.Е. Земляков, В.Х. Кайбышев, Д.Ю. Казанцев, С.И. Трошков, В.И, Егоркин, Б.Я. Бер, Е.В. Луценко, С.В. Иванов, В.Н. Жмерик. Письма в ЖТФ, 42, 57 (2016).

[7] D.S. Frolov, V.I. Zubkov. Semicond. Sci. Technol., 31, 125013 (2016).

[8] I.A. Karpovich, B.N. Zvonkov, N.V. Baidus, S.V. Tikhov, D.O. Filatov. Trends in nanotechnology research (N. Y., Nova Science Publishers, 2004).

[9] J.L. Primus, K-H. Choi, A. Trampert, A.M. Yakunin, J. Ferre, J.H. Wolter, W. Van Roy, J. De Boeck. J. Cryst. Growth, 280, 32 (2005).

[10] T. Mimura. Jpn. J. Appl. Phys., 44, 8263 (2005).

[11] M. Golio, J. Golio. RF and Microwave Passive and Active Technologies (Boca Raton, CRC Press, 2007).

[12] M.M. Pejovic, Milic M. Pejovic. Different Types of Field-Effect Transistors - Theory and Applications (Rijeka, InTech, 2017).

[13] T. Ambridge, M. Faktor. J. Appl. Electrochem., 5, 319 (1975).

[14] В.И. Зубков. Диагностика полупроводниковых наногетероструктур методами спектроскопии адмиттанса (СПб., Элмор, 2007).

[15] Г.Е. Яковлев, Д.С. Фролов, А.В. Зубкова, Е.Е. Левина, В.И. Зубков, А.В. Соломонов, О.К. Стерлядкин, С.А. Сорокин. ФТП, 50, 324 (2016).

[16] V. Zubkov, O. Kucherova, D. Frolov, A. Zubkova. Phys. Status Solidi C, 10, 342 (2013).

[17] Д.С. Фролов, Г.Е. Яковлев, В.И. Зубков, А.Л. Дудин, А.В. Соломникова, Е.С. Кунашик. Изв. СПбГЭТУ „ЛЭТИ“, 2, 6 (2016).

[18] М.В. Дорохин, П.Б. Демина, Н.В. Байдусь, Ю.А. Данилов, Б.Н. Звонков, М.М. Прокофьева. Поверхность, Рентген., синхр. нейтр. исслед., № 5, 34 (2010).

[19] М.В. Дорохин, А.В. Здоровейщев, Е.И. Малышева, Ю.А. Данилов, Б.Н. Звонков, А.Е. Шолина. Поверхность, Рентген., синхр. нейтр. исслед., № 6, 55 (2012). 
[20] М.В. Дорохин, С.В. Зайцев, А.В. Рыков, А.В. Здоровейщев, Е.И. Малышева, Ю.А. Данилов, В.И. Зубков, Д.С. Фролов, Г.Е. Яковлев, А.В. Кудрин. ЖТФ, 87, 1539 (2017).

[21] Б.Н. Звонков, О.В. Вихрова, Ю.А. Данилов, Е.С. Демидов, П.Б. Демина, М.В. Дорохин, Ю.Н. Дроздов, В.В. Подольский, М.В. Сапожников. Оптич. журн., 75, 56 (2008).

[22] I.A. Karpovich, N.V. Baidus', B.N. Zvonkov, S.V. Morozov, D.O. Filatov, A.V. Zdoroveishev. Nanotechnology, 12, 425 (2001).

[23] V.I. Zubkov, M.A. Melnik, A.V. Solomonov, E.O. Tsvelev, F. Bugge, M. Weyers, G. Tränkle. Phys. Rev. B, 70, 075312 (2004).

[24] G. Yakovlev, D. Frolov, V. Zubkov. J. Phys. Conf. Ser., 690, 012015 (2016).

[25] В.И. Зубков. ФТП, 41, 331 (2007).

[26] В.И. Зубков, И.Н. Яковлев, В.Г. Литвинов, А.В. Ермачихин, О.В. Кучерова, В.Н. Черкасова. ФТП, 48, 944 (2014).

[27] А.Н. Петровская, В.И. Зубков. ФТП, 43, 1368 (2009).

[28] Э.Ю. Козловский. Автореф. канд. дис. (Великий Новгород, НовГУ, 2013).

[29] Е.А. Тарасова, Е.С. Оболенская, А.В. Хананова, С.В. Оболенский, В.Е. Земляков, В.И. Егоркин, А.В. Неженцев, А.В. Сахаров, А.Ф. Цацульников, В.В. Лундин, Е.Е. Заварин, Г.В. Медведев. ФТП, 50, 1599 (2016).

[30] А.Л. Дудин, М.С. Миронова, Г.Е. Яковлев, Д.С. Фролов, И.В. Коган, И.В. Шуков, В.И. Зубков, Г.Ф. Глинский. Прикл. физика, 3, 78 (2017).

[31] И.С. Васильевский, Г.Б. Галиев, Е.А. Климов, В.Г. Мокеров, С.С. Широков, Р.М. Имамов, И.А. Субботин. ФТП, 42, 1102 (2008).

[32] M.S. Mironova, V.I. Zubkov, A.L. Dudin, G.F. Glinskii. Proc. 25th Int. Symp. Nanostructures: Physics and Technology (St. Petersburg, Russia, 2017) p. 118.

[33] R. Zucca. J. Appl. Phys., 48, 1987 (1977).

Редактор Л.В. Шаронова

\section{The features of electrochemical capacitance-voltage profiling of GaAs-based LED and pHEMT structures with quantum-confined regions}

G.E. Yakovlev' ${ }^{1}$, M.V. Dorokhin ${ }^{2}$, V.I. Zubkov ${ }^{1}$, A.L. Dudin ${ }^{3}$, A.V. Zdoroveyshchev ${ }^{2}$, E.I. Malysheva ${ }^{2}$, Yu.A. Danilov', B.N. Zvonkov' ${ }^{2}$, A.V. Kudrin ${ }^{2}$

${ }^{1}$ St. Petersburg State Electrotechnical University "LETI“, 197376 St. Petersburg, Russia

${ }^{2}$ Physical-Technical Research Institute of Lobachevsky State University of Nizhny Novgorod, 603950 Nizhny Novgorod, Russia

3 JCS "Svetlana-Rost", 194156 St. Petersburg, Russia

Abstract The GaAs-based light-emitting and HEMT-structures with $\delta$-doping regions, InGaAs/GaAs quantum wells and near-surface InAs/GaAs quantum dots were studied by means of electrochemical capacitance-voltage profiling technique. The profiles of free charge carrier depth distribution have been obtained, the accumulated in quantum wells and quantum dots space charge and doping level in emitter and $\delta$-layers have been determined. The line-up potential and free carrier density distribution along the depth of the samples with different quantum well geometry are simulated. The features of electrochemical capacitance-voltage profiling in case of different type structures are analyzed. For effective separation of responses from close-located layers, in particular a quantum well and a $\delta$-layer, the integrating technique of capacitance-voltage characteristics at each etching step is proposed. 